\title{
A dye-sensitized solar cell based on PEDOT:PSS counter electrode
}

\author{
YUE GenTian, WU JiHuai*, XIAO YaoMing, LIN JianMing, HUANG MiaoLiang, \\ FAN LeQing \& YAO Ying \\ Engineering Research Center of Environment-Friendly Functional Materials, Ministry of Education, Institute of Materials Physical Chemistry, \\ Huaqiao University, Quanzhou 362021, China
}

Received April 25, 2012; accepted May 10, 2012

\begin{abstract}
A counter electrode for dye-sensitized solar cell (DSSC) was prepared by coating poly(3,4-ethylenedioxythiophene): poly(styrenesulfonate) (PEDOT:PSS) with high transparency and adhesion on a conducting FTO glass at low temperature. The surface morphology, conductivity, sheet resistance, redox properties and photoelectric properties of the PEDOT:PSS/carbon electrodes were observed using scanning electron microscopy, a four-probe tester and a CHI660D electrochemical measurement system. The experimental results showed that DSSCs had the best photoelectric properties for PEDOT:PSS/carbon counter electrodes annealed at $80^{\circ} \mathrm{C}$ under vacuum conditions. The overall energy conversion efficiency of the DSSC with PEDOT:PSS/carbon counter electrode and barrier layer reached $7.61 \%$ under irradiation from a simulated solar light with intensity of $100 \mathrm{~mW} / \mathrm{cm}^{2}$ (AM 1.5). The excellent photoelectric properties, simple preparation procedure and low cost allow the PEDOT:PSS/carbon electrode to be a credible alternative electrode for use in DSSCs.
\end{abstract}

PEDOT:PSS, counter electrode, $\mathrm{TiO}_{2}$ film, dye-sensitized solar cell

Citation: Yue G T, Wu J H, Xiao Y M, et al. A dye-sensitized solar cell based on PEDOT:PSS counter electrode. Chin Sci Bull, 2013, 58: 559-566, doi: $10.1007 / \mathrm{s} 11434-012-5352-3$

Dye-sensitized solar cell (DSSC) based on the sensitization of nanocrystalline $\mathrm{TiO}_{2}$ by photoexcited dye molecules have been investigated intensively, and have made great progress since Gratzel [1-2] made the breakthrough on the DSSC in 1991. The DSSC became a new research focus because of its lower cost, simple fabrication process, high theoretical photoelectric conversion efficiency and its potential as an alternative to traditional photovoltaic devices, which have been researched from a basic small area in the laboratory to large area production. To date, DSSCs based on liquid electrolytes have reached efficiencies of more than $11 \%$ under AM1.5 illumination [3].

In general, DSSCs consists of a sandwich structure with a porous nanocrystalline $\mathrm{TiO}_{2}$ film electrode sensitized by a dye to absorb visible light, a redox electrolyte, and a platinized counter electrode to collect electrons and catalyze the $\mathrm{I}_{2} / \mathrm{I}^{-}$redox-coupled regeneration reaction in the electrolyte

*Corresponding author (email: jhwu@ @qu.edu.cn)
[4]. The DSSC works as follows: a porous network of nanosize $\mathrm{TiO}_{2}$ particles serves as a charge-transport medium, on which a monolayer of dye molecules is chemically adsorbed. Upon illumination, electrons are injected from the photoexcited dye into the conduction band of $\mathrm{TiO}_{2}$, while the holes shuttle toward the counter electrode through an iodide/triiodide $\left(\mathrm{I}^{-} / \mathrm{I}_{3}{ }^{-}\right)$redox electrolyte. After this process is performed, the electron reaches the counter electrode and reduces the $\mathrm{I}_{3}{ }^{-}$ion and the electrical circuit is completed [5].

At present, the research on dye-sensitized solar cells is focused on the dye synthesis [6,7], electron transport process [8], photoanode [9-12], solid-state (or quasi-solid) electrolyte [13-15] and counter electrode. The counter electrode is an important component of the DSSC, usually containing platinum and conductive glass, which have a high performance capability for the catalytic to $\mathrm{I}_{3}{ }^{-}$process in the electrolyte, and enable efficient charge transfer at the electrode/electrolyte interfaces. However, platinum as the conventional counter-electrode material for the devices is a 
burden for large-scale DSSC applications, because it is one of the most expensive materials available. So, the important challenge for the DSSC is development of low-cost and platinum-free counter-electrode materials with relatively high conversion efficiency. However, the desired counter-electrode materials with high electrical conductivity and superior electrocatalytic activity are rare. $\mathrm{Wu}$ et al. [16] synthesised tungsten oxide $\left(\mathrm{WO}_{2}\right)$, tungsten carbide (WC) and molybdenum carbide (MoC) to replace the Pt electrode, assembled the DSSCs, and produced a photoelectric conversion efficiency of more than 7\%; Wu et al. [17] used carbon nanotubes and titanium nitride as the electrode materials, prepared a low-cost dye-sensitized solar cell, and measured an efficiency of $5.41 \%$; Jeon et al. [18] used pyrrole as the raw material on the DSSC electrode, and the efficiency reached $6.83 \%$.

In this paper, using the high transparency and good adhesion of the conductive polymer poly $(3,4$ - ethylenedioxythiophene): poly (styrenesulfonate) (PEDOT:PSS), we added low cost graphite powder and carbon black, dimethyl sulfoxide, polyethylene glycol 400, and a small amount of polyvinylpyrrolidone to prepare a conductive paste; we then obtained a new type of PEDOT:PSS/carbon electrode after low temperature sintering, which has some obvious advantages, as follows:

(1) Greater freedom of choice of substrate material, including ordinary glass, plastic, and stainless steel.

(2) PEDOT:PSS and graphite carbon have good conductivity, which meant that the prepared electrode has high conductivity and low resistivity compared with $\mathrm{Pt}$ electrodes.

(3) Graphite and carbon black are low cost materials.

(4) PEDOT:PSS has good substrate adhesion, so the preparation process for the electrode film is simple, with a low annealing temperature, and high efficiency.

In this paper, the new PEDOT:PSS/carbon electrode conductivity, catalytic activity and surface morphology were studied, and the electrode was used in DSSCs. We discussed the effects of temperature and heat treatment conditions on the performance of the DSSCs.

\section{Experimental}

\subsection{Materials and instruments}

The poly (3,4-ethylenedioxythiophene): poly (styrenesul-

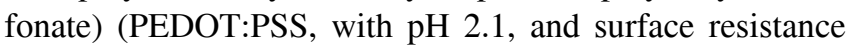
$\left.(\Omega / \mathrm{sq})=1 \times 10^{5}-3 \times 10^{5}\right)$ came from Shanghai Chunyuan Phytochemistry Co., Ltd, China. The anhydrous ethanol (ETOH), isopropanol, nitric acid $\left(\mathrm{HNO}_{3}\right)$, acetic acid (HAc), DMSO, graphite, carbon black, polyvinylpyrrolidone (PVP), polyethylene glycols with average molecular weights of 20000 and 400 (PEG-20000 and PEG-400) and OP emulsification agent (Triton $\mathrm{X}-100)$, tetrabutyltitanate $\left[\mathrm{Ti}(\mathrm{OBu})_{4}\right]$ and titanium tetrachloride $\left(\mathrm{TiCl}_{4}\right)$ were analytical grade purity and were purchased from Shanghai Chemical Agent Ltd, China. The organometallic compound sensitized dye N-719 [RuL $2(\mathrm{NCS})_{2}$, L 4,4'-dicarboxylate-2,2'-bipyridine] was obtained from Solaronix SA (Switzerland). All reagents were used without further treatment before use.

A conductive glass plate (FTO glass, with fluorine doped tin oxide over-layer having sheet resistance of $8 \Omega \mathrm{cm}^{-2}$, purchased from Hartford Glass Co., USA) was used as a substrate for precipitation of the $\mathrm{TiO}_{2}$ porous film and was cut into $1 \mathrm{~cm} \times 2 \mathrm{~cm}$ sheets.

\subsection{Preparation of dye-sensitized $\mathrm{TiO}_{2}$ film}

A $\mathrm{TiO}_{2}$ nanoporous film was prepared by the following procedure [19]. Tetrabutyltitanate $(10 \mathrm{~mL})$ was rapidly added to distilled water $(100 \mathrm{~mL})$ and a white precipitate was immediately formed. The precipitate was filtered using a glass frit and washed with distilled water. Under vigorous stirring, the filter cake was added to a $1 \mathrm{~mL}$ nitric acid and $10 \mathrm{~mL}$ acetic acid aqueous solution $(150 \mathrm{~mL})$ at $80^{\circ} \mathrm{C}$, until the slurry became a translucent blue-white liquid. The blue-white liquid was autoclaved at $200^{\circ} \mathrm{C}$ for $12 \mathrm{~h}$ to form a milky white slurry. The slurry was concentrated down to $1 / 4$ of its original volume, and then PEG-20000 (10 wt.\% slurry) and a few drops of the emulsification agent Triton $\mathrm{X}-100$ were added to form a $\mathrm{TiO}_{2}$ colloid.

A conductive glass sheet (FTO) was immersed in an isopropanol solution for $48 \mathrm{~h}$ to remove any surface impurities. It was then cleaned in a Triton X-100 aqueous solution, washed with ethanol, and treated with a $50 \mathrm{mmol} \mathrm{L}^{-1} \mathrm{TiCl}_{4}$ aqueous solution at $70^{\circ} \mathrm{C}$ for $30 \mathrm{~min}$ to produce a good interfacial contact between the $\mathrm{TiO}_{2}$ layer and the conductive glass substrate.

To reduce the recombination of the electrons on the conductive glass with the holes, a barrier layer was coated on the conductive glass using the following procedure [20]: tetrabutyltitanate was dissolved in ethanol; acetylacetone, acting as an inhibitor, was added to abate the hydrolysis reaction of tetrabutyltitanate. Under vigorous stirring, a nitric acid and acetic acid mixed water-ethanol solution was added, which led to the hydrolysis of the tetrabutyltitanate and a stable $\mathrm{TiO}_{2}$ colloid was obtained. The molar ratio of $\mathrm{Ti}(\mathrm{OBu})_{4}: \mathrm{ETOH}: \mathrm{H}_{2} \mathrm{O}: \mathrm{HNO}_{3}: \mathrm{HAc}$ was controlled at $1: 8$ : $2: 0.2: 0.5$. Terpineol was added to adjust the viscosity of the colloid. The $\mathrm{TiO}_{2}$ colloid was coated on the FTO glass plate using a doctor scraping technique. After sintering at $500^{\circ} \mathrm{C}$ for $30 \mathrm{~min}$ in air, the barrier layer with a $\mathrm{TiO}_{2}$ particle size of $5 \mathrm{~nm}$ and thickness of $1 \mu \mathrm{m}$ covered the surface of the FTO plate.

A transparent adhesive tape was fixed around the four sides of the conductive glass sheet to restrict the thickness and area of the $\mathrm{TiO}_{2}$ film [21]. The above $\mathrm{TiO}_{2}$ colloid was coated on the FTO glass plate using the doctor scraping technique. Finally, the $\mathrm{TiO}_{2}$ film was hardened by firing the FTO glass sheet at $450^{\circ} \mathrm{C}$ in air for $30 \mathrm{~min}$. The process was 
repeated twice to form a $\mathrm{TiO}_{2}$ film of about $6-8 \mu \mathrm{m}$ in thickness. After cooling down to $80^{\circ} \mathrm{C}$, the FTO glass was immersed in a $0.5 \mathrm{mmol} \mathrm{L}{ }^{-1}$ absolute ethanol solution of dye N719 for $24 \mathrm{~h}$ to absorb the dye adequately, and then the dye-sensitized $\mathrm{TiO}_{2}$ film was washed and dried in moisture-free air.

\subsection{Preparation of PEDOT:PSS/carbon electrode}

A certain amount of PEDOT:PSS (a schematic diagram of the structure is shown in Figure 1(a)) solution mixed with DMSO, which is a polar solvent, was added into a beaker, making a volume ratio of $4.5: 1$, and then stirred at room temperature for 5 to $6 \mathrm{~h}$ to produce an evenly mixed solution and reach a certain viscosity; the original solution of PEDOT:PSS/carbon was obtained by adding a small amount of graphite powder and PVP and stirring for $12 \mathrm{~h}$ at room temperature. Twenty milliliter of the PEDOT:PSS/ carbon original solution was stirred for $6 \mathrm{~h}$ at room temperature after adding a small amount of PEG400, and then a PEDOT:PSS/carbon conductive solution was prepared. The PEDOT:PSS/carbon conductive solution was coated on the FTO conductive glass under infrared light irradiation with a scratch method, producing a film thickness of 3-4 $\mu \mathrm{m}$, and was vacuum annealed at $80^{\circ} \mathrm{C}$.

\subsection{Fabrication of dye-sensitized solar cell}

The DSSC was assembled by injecting an electrolyte into the aperture between the $\mathrm{TiO}_{2}$ film electrode (anode electrode) and the PEDOT:PSS/carbon counter electrode. The electrolyte consisted of $0.60 \mathrm{~mol} \mathrm{~L}^{-1}$ tetrabutyl ammonium iodide, $0.10 \mathrm{~mol} \mathrm{~L}^{-1}$ iodine, and $0.50 \mathrm{~mol} \mathrm{~L}^{-1} 4$-tert-butylpyridine in acetonitrile. The two electrodes in a "sandwich" structure $[22,23]$ were clipped together and a cyanoacrylate adhesive was used as a sealant to seal the solar cell. We then obtained a DSSC with PEDOT:PSS/carbon counter electrode, as shown in Figure 1(b).

\subsection{Measurements}

The micromorphology of the PEDOT:PSS/carbon electrode was observed by using a JSM-6700F field emission scanning electron microscope (FESEM). The conductivity of the PEDOT:PSS/carbon electrode was tested using an RTS-9 model 4-point probe resistivity measurement system. Cyclic voltammetry $(\mathrm{CV})$ measurements of the samples were taken in a three-electrode one-compartment cell with a PEDOT: PSS/carbon coating on an FTO working electrode, a Pt foil counter electrode and an $\mathrm{Ag} / \mathrm{AgCl}$ reference electrode dipped in an acetonitrile solution of $10 \mathrm{mmol} \mathrm{L}^{-1} \mathrm{LiI}, 1$ mmol L${ }^{-1} \mathrm{I}_{2}$, and $0.1 \mathrm{mmol} \mathrm{L}^{-1} \mathrm{LiClO}_{4}$. $\mathrm{CV}$ was performed using the CHI660D electrochemical measurement system (scan conditions: $40-200 \mathrm{mV} \mathrm{s}^{-1}$ ).

The photovoltaic testing of the DSSCs was carried out by (a)
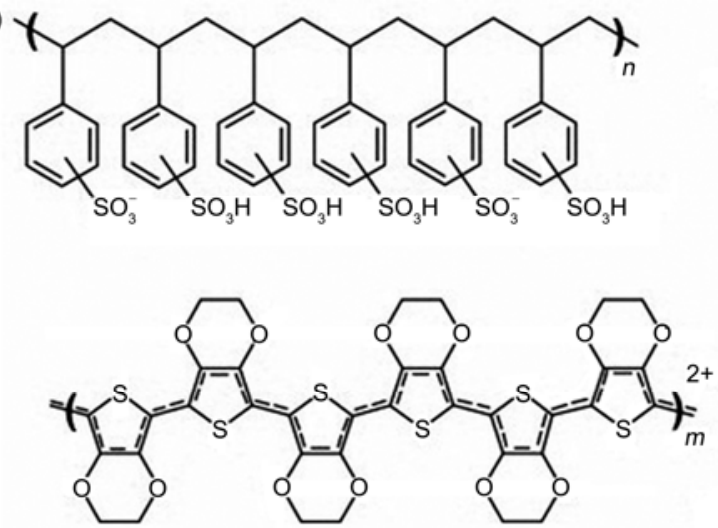

(b)

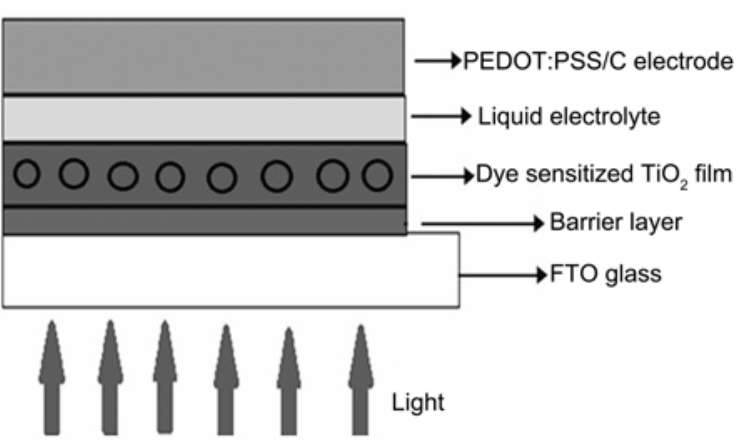

Figure 1 (a) The structure of PEDOT:PSS; (b) a schematic diagram of the DSSC.

measuring photocurrent-photovoltage $(J-V)$ characteristic curves under white light irradiation of $100 \mathrm{~mW} / \mathrm{cm}^{2}$ (AM1.5) from a solar simulator (XQ-500W, Shanghai Photoelectricity Device Company, China) in an ambient atmosphere and using a computer controlled voltage current source-meter of the CHI660D electrochemical measurement system. The incident light intensity and the active cell area were 100 $\mathrm{mW} \mathrm{cm}$ and $0.5 \mathrm{~cm}^{2}$, respectively. The fill factor $(F F)$ and the light-to-electric energy conversion efficiency $(\eta)$ of the solar cell were calculated according to the following equations [2]:

$$
\begin{gathered}
F F=\frac{V_{\text {max }} \times J_{\text {max }}}{V_{\mathrm{oc}} \times J_{\mathrm{sc}}}, \\
\eta=\frac{P_{\text {max }}}{P_{\mathrm{in}}}=\frac{J_{\mathrm{sc}} \times V_{\mathrm{oc}} \times F F}{P_{\mathrm{in}}},
\end{gathered}
$$

where $J_{\mathrm{SC}}$ is the short-circuit current density $\left(\mathrm{mA} \mathrm{cm}{ }^{-2}\right)$, $V_{\mathrm{OC}}$ is the open-circuit voltage $(\mathrm{V}), P_{\text {in }}$ is the incident light power, and $\left.J_{\max }(\mathrm{mA} \mathrm{cm})^{-2}\right)$ and $V_{\max }(\mathrm{V})$ are the current density and voltage at the point of maximum power output in the $J$ - $V$ curves, respectively.

\section{Results and discussion}

\subsection{Morphology and compositions of PEDOT:PSS/ carbon electrode}

Figure 2 shows the SEM image of the PEDOT:PSS/carbon 


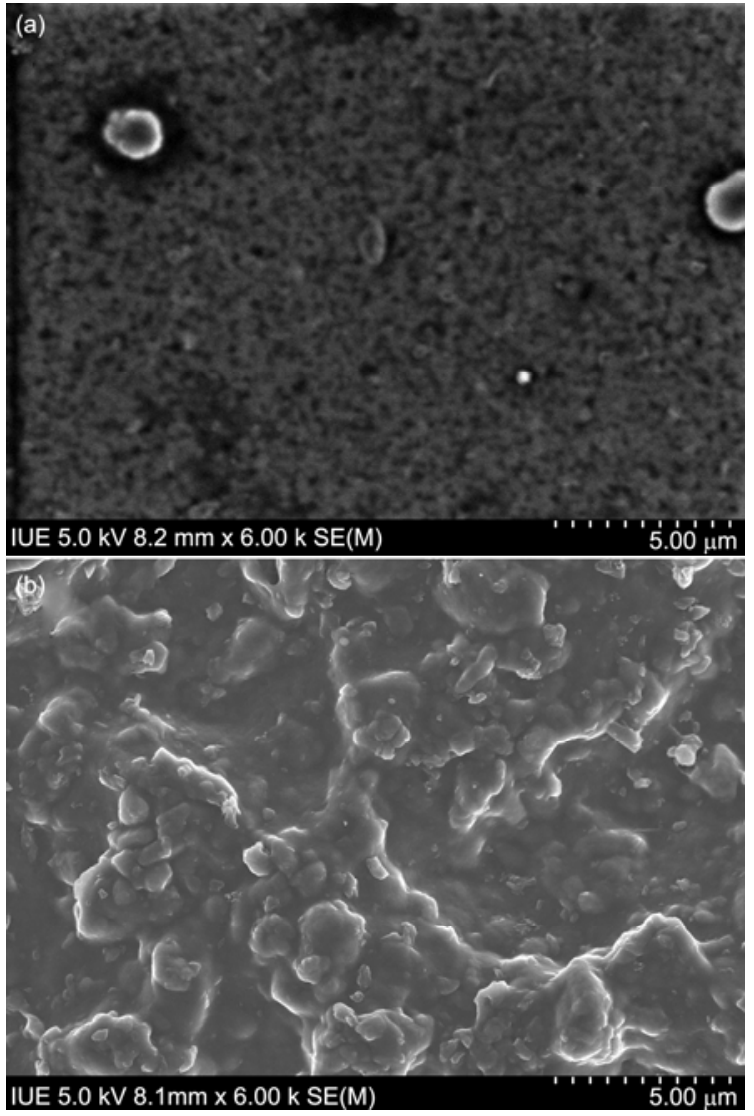

Figure 2 (a) SEM image of PEDOT:PSS film; (b) SEM image of PEDOT:PSS/C composite film with dimethyl sulfoxide.

electrode. It was clear that the electrode surface was smooth, and had lower roughness before addition of graphite carbon (Figure 2(a)). The surface of the electrode clearly showed an coarse surface when mixed with graphite carbon (Figure 2(b)), which increased the surface area of the electrode and was good for improving contact between the anode and the PEDOT:PSS/carbon electrode by trapping the electrolyte solution.

\subsection{Electrochemical properties of PEDOT:PSS/carbon electrode}

Cyclic voltammetry was carried out using a Pt electrode or a PEDOT:PSS/carbon electrode as the working electrode. A Pt coil was used as the counter electrode, and an $\mathrm{Ag} / \mathrm{Ag}^{+}$ electrode was used as reference electrode. The electrolyte was the acetonitrile solution containing $0.1 \mathrm{M} \mathrm{LiClO}_{4}$ as the supporting electrolyte and $10 \mathrm{mmol} \mathrm{L}{ }^{-1} \mathrm{LiI}$ with $1 \mathrm{mmol} \mathrm{L}^{-1}$ $\mathrm{I}_{2}$ as the redox couple.

Figure 3 shows cyclic voltammograms of the $\mathrm{I}_{2} / \mathrm{I}^{-}$system for the PEDOT:PSS/carbon electrode and the Pt electrode at a scan rate of $50 \mathrm{mV} \mathrm{s}^{-1}$. The more negative pair is assigned to reduction reaction of $\mathrm{I}_{3}^{-}$(eqs. (3) and (4), and the more positive pair is assigned to oxidation reaction of $\mathrm{I}^{-}$(eqs. (5) and (6)) [24]:

$$
\begin{gathered}
\mathrm{I}_{3}^{-}+2 \mathrm{e}^{-} \rightarrow 3 \mathrm{I}^{-} \\
\mathrm{I}_{2}+2 \mathrm{e}^{-} \rightarrow 2 \mathrm{I}^{-} \\
3 \mathrm{I}^{-}-2 \mathrm{e}^{-} \rightarrow \mathrm{I}_{3}^{-} \\
2 \mathrm{I}^{-}-2 \mathrm{e} \rightarrow \mathrm{I}_{2}
\end{gathered}
$$

In the DSSC, electrons are injected into photooxidized dye from $\mathrm{I}^{-}$ions in the electrolyte (eqs. (5) and (6)), and the produced $\mathrm{I}_{3}{ }^{-}$ions are reduced on the counter electrode (eqs. (3) and (4)). Figure 3 showed a much higher current density at the $\mathrm{I}_{3}{ }^{-}$reduction peak for the PEDOT:PSS/carbon electrode than for the Pt electrode. This suggests a faster reaction rate on the PEDOT:PSS/carbon electrode than on the Pt electrode. In other words, the charge-transfer resistance (Rct) for $\mathrm{I}^{-} / \mathrm{I}_{3}{ }^{-}$redox reaction is smaller on the PEDOT:PSS/ carbon electrode than on the Pt electrode under the same conditions. Also, it can be clearly seen that the formal potential shifted to a more positive and larger oxidation-reduction current density for the PEDOT:PSS/carbon electrode than for the Pt electrode in Figure 3. Thus, the PEDOT:PSS/ carbon electrode has higher electrocatalytic activity in the $\mathrm{I}^{-} / \mathrm{I}_{3}^{-}$redox reaction than that of the $\mathrm{Pt}$ particles. However, the reduction peak on the left was not clear for the PEDOT:PSS/carbon electrode [25], which may be due to the restrain of reaction (4) on the PEDOT:PSS/carbon electrode. This indicates that the PEDOT:PSS/carbon electrode can be used as an efficient electrocatalyst counter electrode for DSSCs.
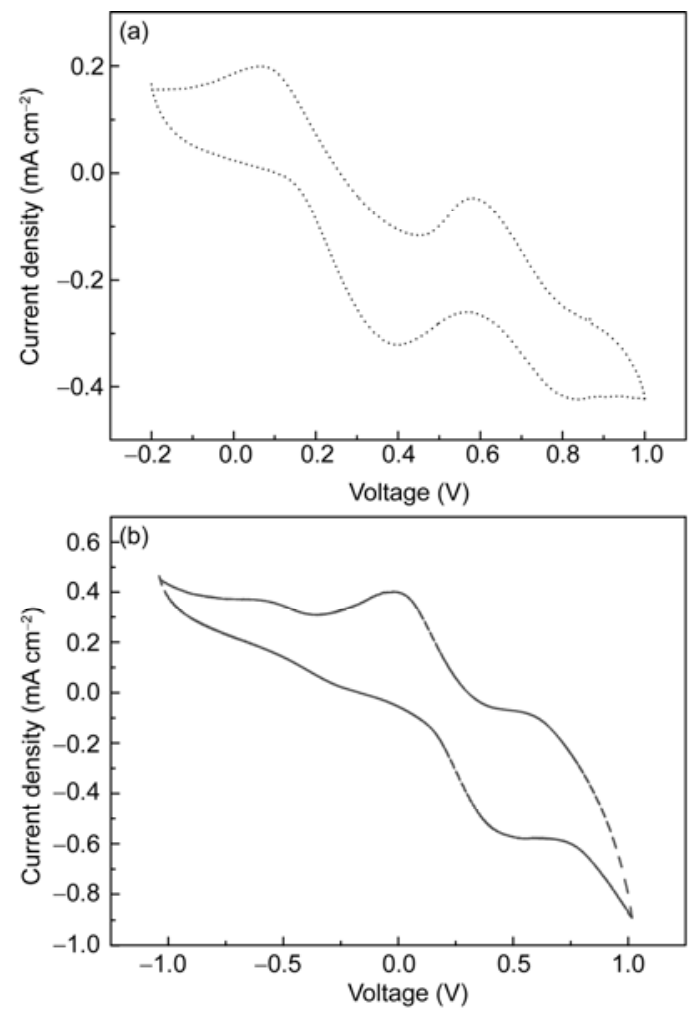

Figure 3 Cyclic voltammograms of the $\mathrm{Pt}$ electrode and the PEDOT:PSS/carbon electrode at a scan rate of $50 \mathrm{mV} \mathrm{s}^{-1}$. 
Figure 4(a) shows consecutive cyclic voltammograms of the $\mathrm{I}_{2} / \mathrm{I}^{-}$system for the PEDOT:PSS/carbon electrode. Two redox couples are observed. On successive scans, the peak current densities change with the change in scan rate. This indicates that the PEDOT:PSS/carbon was coated tightly on the FTO glass surface. Both redox peak currents show a good linear relationship with the cycle times, as shown in Figure 4(b). It also therefore indicates that the PEDOT:PSS/ carbon film electrode is uniform and homogeneous [26,27].

\subsection{Influence of the temperature on the conductivity properties of the PEDOT:PSS/carbon electrode}

The temperature and annealing environment had a major influence on the conductivity, resistivity and sheet resistance of the PEDOT:PSS/carbon electrode, as shown in Figure 5, Tables 1 and 2. It is found clearly that the trends of conductivity, resistivity and sheet resistance change, although these values are only an approximation using the four-electrode method. Series 1 was annealed in vacuum and series 2 was annealed in the atmosphere as shown in Figure 5, so that the conductivities increased as the heating temperature grew, and then decreased at $80^{\circ} \mathrm{C}$, where we had maximum values of about 1.73 and $1.72 \mathrm{~S} / \mathrm{cm}$,
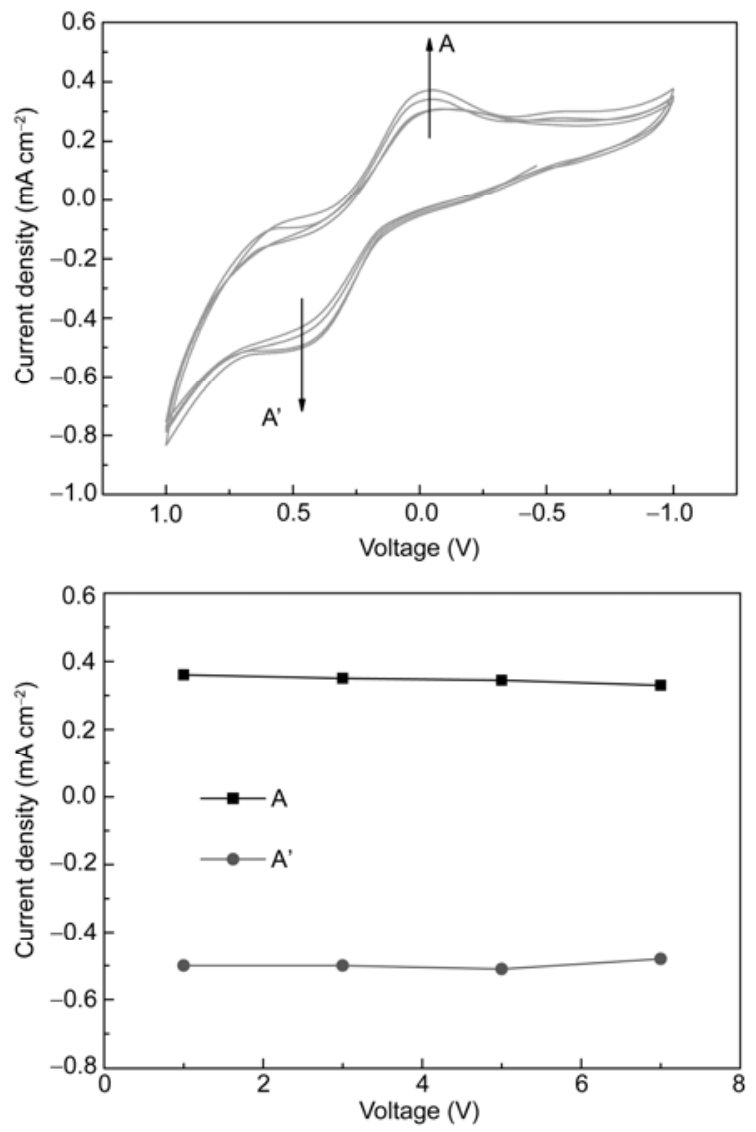

Figure 4 (a) Four consecutive cyclic voltammograms of $\mathrm{I}_{2} / \mathrm{I}^{-}$system for PEDOT:PSS/carbon electrode and scan rate $=50 \mathrm{mV} \mathrm{s}^{-1}$; (b) the relationship between the cycle times and the redox peak currents for the PEDOT:PSS/ carbon electrode. respectively; the values of the resistivity and sheet resistance were opposite, and had minimum values at $80^{\circ} \mathrm{C}$. The curve of series 1 was higher than that of series 2 , because the vacuum environment has less $\mathrm{H}_{2} \mathrm{O}$ and $\mathrm{O}_{2}$ than the atmosphere, and it had less of an impact on the PEDOT:PSS/carbon electrode.

The maximum conductivity of the vacuum annealed electrode was higher than that of the atmosphere annealed electrode, which is mainly due to $\mathrm{H}_{2} \mathrm{O}$ and $\mathrm{O}_{2}$ under the vacuum having less impact on the electrode relative to the other series, although the heating time was longer because the heat absorption rate was faster for the heating plate than that in the vacuum. On the other hand, the increasing or decreasing conductivity with increasing temperature was also affected by the transmission mechanism of PEDOT: PSS [28,29]. The particle size and the conductance between the particles of PEDOT:PSS controlled the conductivity; at the right temperature, the connections between the PSS and PEDOT particles were dissolved and softened, and the number and height of the obstacles were reduced, which will be more favorable for the directional growth of crystallization of the polymer chains; thermal mass loss led to the decreased conductivity with continued heating. In conclusion, Figure 5, Tables 1 and 2 indicate that annealing improved the conductivity of the PEDOT:PSS/ carbon electrode.

\subsection{Incident photon-to-current efficiency (IPCE)}

Figure 6 compares the IPCEs of DSSCs for PEDOT:PSS/ carbon electrodes and Pt electrodes. The DSSCs had good photoelectric responses in the 300-370 nm (UV area) and 375-700 $\mathrm{nm}$ (visible area) ranges. The IPCEs in the UV range were mainly caused by the absorption of the $\mathrm{TiO}_{2}$ film $[22,28]$, which has an absorption peak around $330 \mathrm{~nm}$ for the direct band gap photoelectron excitation. From Figure 6 we see that the IPCEs of DSSCs with PEDOT:PSS/ carbon electrodes had high absorption of $35.5 \%$ in the $375-700 \mathrm{~nm}$ (visible area), which is only $9.9 \%$ lower than for the DSSC assembled using a Pt electrode (39.4\%). This indicates that the PEDOT:PSS/carbon electrode shows good catalytic properties, and that it is a promising replacement for $\mathrm{Pt}$ as the counter electrode material for DSSCs.

\subsection{Photovoltaic performance of DSSC with PEDOT: PSS/carbon electrode}

To evaluate the effect of annealing temperature on the solar cell, the $J-V$ curves for the DSSCs with different annealing temperatures $\left(40,60,80,100,120\right.$, and $\left.140^{\circ} \mathrm{C}\right)$ were measured under standard light irradiation and are shown in Figure 7 , and the photoelectric parameters are summarized in Table 3. Compared with the DSSC using a Pt electrode, the open circuit voltage of the DSSC assembly using the PEDOT:PSS/carbon electrode is higher, and the conversion efficiency is a close match. In particular, the PEDOT:PSS/ 
Table 1 Influence of temperature on the conductivity, resistivity and sheet resistance of PEDOT:PSS/carbon electrode in atmospheric annealing environment

\begin{tabular}{cccc}
\hline $\begin{array}{c}\text { Temperature } \\
\left({ }^{\circ} \mathrm{C}\right)\end{array}$ & $\begin{array}{c}\text { Resistivity } \\
(\Omega \mathrm{m})\end{array}$ & $\begin{array}{c}\text { Conductivity } \\
(\mathrm{S} / \mathrm{m})\end{array}$ & $\begin{array}{c}\text { Sheet resistance } \\
(\Omega / \square)\end{array}$ \\
\hline 40 & 0.0069 & 146 & 14.27 \\
60 & 0.0069 & 153 & 13.56 \\
80 & 0.0061 & 172 & 11.94 \\
100 & 0.0064 & 157 & 13.37 \\
120 & 0.0066 & 153 & 13.78 \\
140 & 0.0072 & 143 & 14.17 \\
\hline
\end{tabular}

Table 2 Influence of temperature on the conductivity, resistivity and sheet resistance of PEDOT:PSS/carbon electrode in vacuum annealing environment

\begin{tabular}{cccc}
\hline $\begin{array}{c}\text { Temperature } \\
\left({ }^{\circ} \mathrm{C}\right)\end{array}$ & $\begin{array}{c}\text { Resistivity } \\
(\Omega \mathrm{m})\end{array}$ & $\begin{array}{c}\text { Conductivity } \\
\left(\mathrm{S} \mathrm{m}^{-1}\right)\end{array}$ & $\begin{array}{c}\text { Sheet resistance } \\
(\Omega / \square)\end{array}$ \\
\hline 40 & 0.0067 & 156 & 14.27 \\
60 & 0.0063 & 159 & 13.56 \\
80 & 0.0059 & 173 & 11.94 \\
100 & 0.0061 & 159 & 13.37 \\
120 & 0.0064 & 157 & 13.78 \\
140 & 0.0067 & 152 & 14.17 \\
\hline
\end{tabular}

Table 3 The influence of annealing temperatures on the photovoltaic properties of the DSSC

\begin{tabular}{ccccc}
\hline $\begin{array}{c}\text { Temperature } \\
\left({ }^{\circ} \mathrm{C}\right)\end{array}$ & $\begin{array}{c}V_{\text {oc }} \\
(\mathrm{V})\end{array}$ & $\begin{array}{c}J_{\text {sc }} \\
\left(\mathrm{mA} \mathrm{cm}^{-2}\right)\end{array}$ & $F F$ & $\begin{array}{c}\eta \\
(\%)\end{array}$ \\
\hline 40 & 0.74 & 11.8 & 0.54 & 5.0 \\
60 & 0.80 & 12.7 & 0.66 & 6.7 \\
80 & 0.81 & 13.6 & 0.69 & 7.6 \\
100 & 0.75 & 12.4 & 0.61 & 5.5 \\
120 & 0.72 & 12.2 & 0.60 & 5.4 \\
140 & 0.74 & 12.0 & 0.60 & 5.3 \\
\hline
\end{tabular}

carbon electrode showed excellent electrochemical catalytic activity, which was comparable to the performance of $\mathrm{Pt}$, and achieved energy conversion efficiency of $7.61 \%$, which was only $6.9 \%$ lower than that of the Pt-based DSSC.

The improvement in the photoelectric performance for DSSCs based on PEDOT:PSS/carbon counter electrodes is mainly due to the following aspects. First, the counter electrode with the uplift structure engendered a large surface area for the electrode, which helped to increase the cycle rate of the $\mathrm{I}_{2} / \mathrm{I}_{3}{ }^{-}$redox reaction in the electrolyte. The photoelectric performance of the DSSC can be improved by the increase in the surface area of the electrode. Second, the higher conductivity and smaller resistance increased the transmission capacity of the electrons and holes between the electrolyte and the PEDOT:PSS/carbon electrode [30-32]. Also, the DSSC barrier layer meant a reduction in the recombination of the photo-induced electrons with free charge carriers on the conductive glass substrate, increased the numbers of photoelectrons from the external circuit reaching
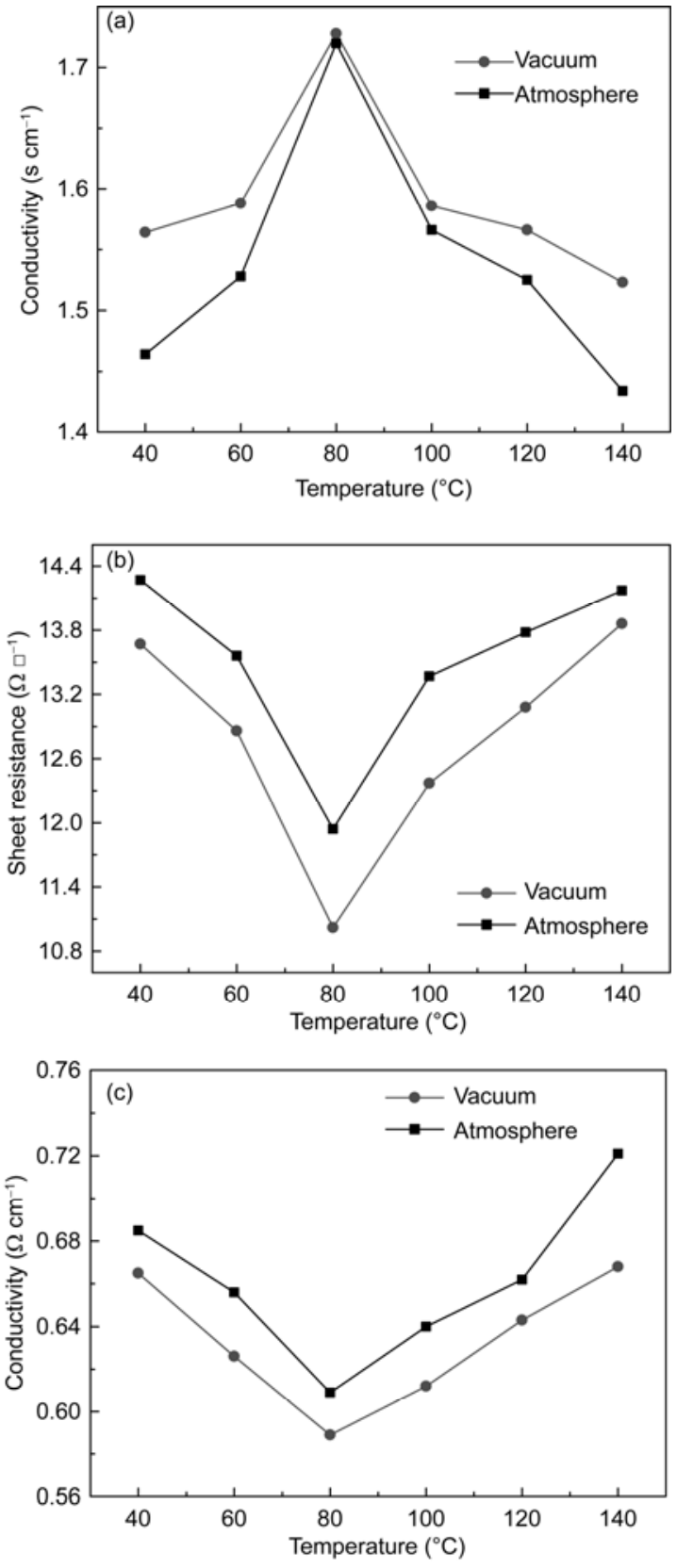

Figure 5 Influence of the temperature on (a) conductivity, (b) sheet resistance, and (c) resistivity of the PEDOT:PSS/carbon electrode in different annealing environments.

the photocathode, and led to a reduction in the dark current, which helped to improve photocurrent density. The present findings demonstrated that the DSSCs with the PEDOT:PSS/carbon electrodes have the predominant photovoltaic performance.

\section{Conclusions}

In conclusion, PEDOT:PSS/carbon conductive paste was 


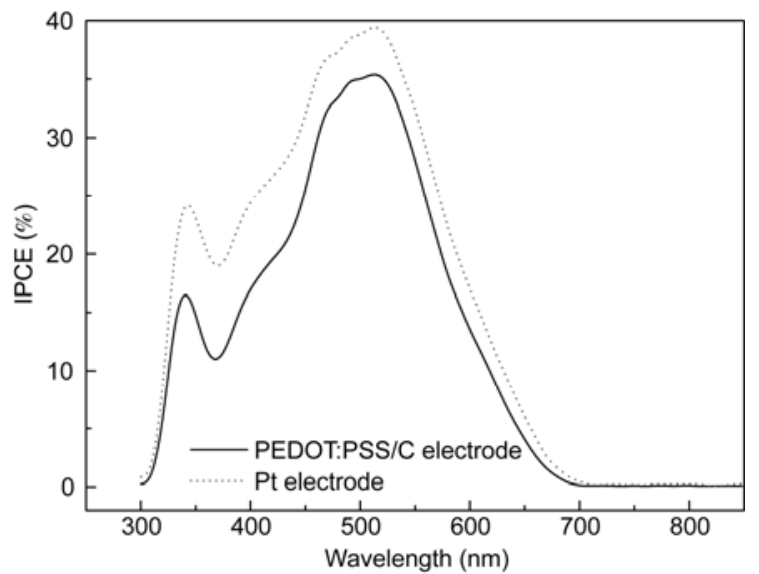

Figure 6 IPCEs of DSSCs with PEDOT:PSS/carbon and Pt counter electrodes.
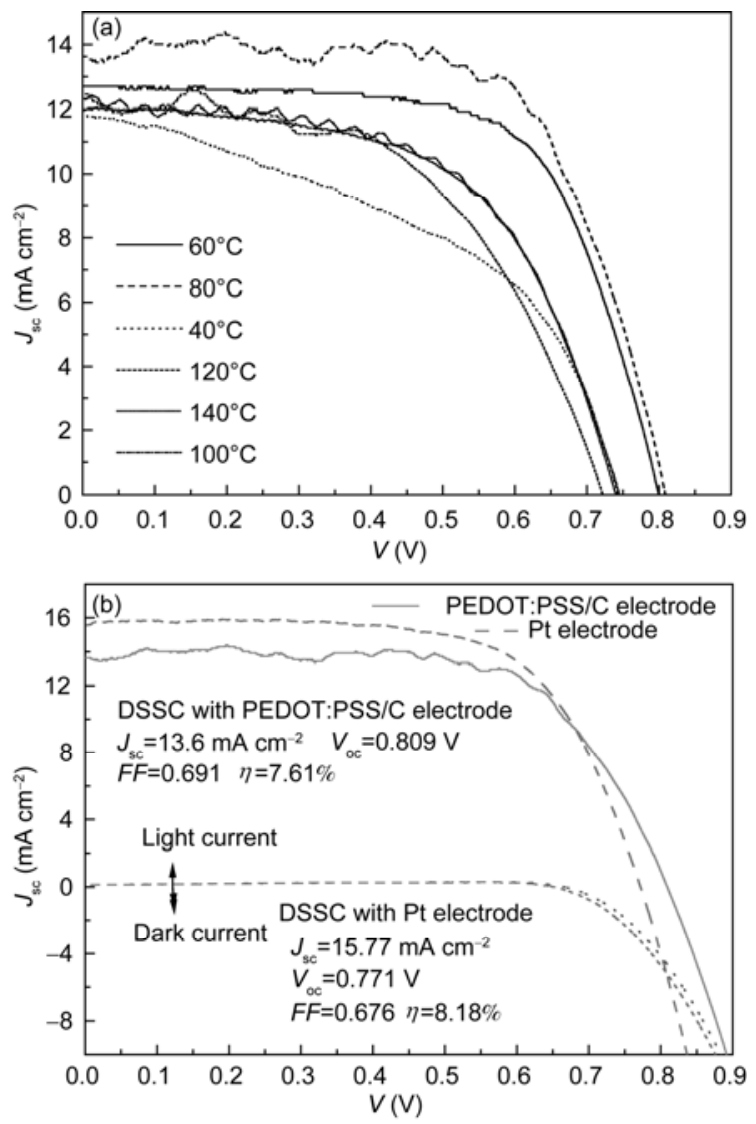

Figure 7 (a) $J-V$ curves for DSSCs using PEDOT:PSS/carbon counter electrode with different annealing temperatures; (b) $J-V$ curves for DSSCs with PEDOT:PSS/carbon and Pt electrode.

prepared by adding graphite powder, carbon black, dimethyl sulfoxide, polyethylene glycol and a small amount of polyvinylpyrrolidone to a PEDOT:PSS solution, and then coated on FTO substrate to construct a PEDOT:PSS/carbon counter electrode for the dye-sensitized solar cells (DSSCs). The surface morphology of the PEDOT:PSS/carbon electrode was observed to have an coarse surface, which provided a larger surface area for the electrode; there were also good electrochemical properties produced under $80^{\circ} \mathrm{C}$ vacuum annealing, such as higher conductivity, smaller sheet resistance, better redox properties and better photoelectric properties. The overall energy conversion efficiency of the DSSC with the PEDOT:PSS/carbon counter electrode reached $7.61 \%$ under irradiation of simulated solar light

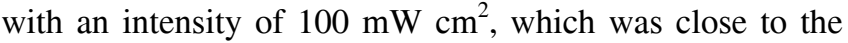
overall energy conversion efficiency of the DSSC based on a Pt counter electrode. The excellent photoelectric properties, simple preparation procedure and low cost show that the PEDOT:PSS/carbon electrode is a credible alternative electrode for use in DSSCs.

This work was supported by the National High Technology Research and Development Program of China (2009AA03Z217), and the National Natural Science Foundation of China (90922028).

1 O'Regan B, Grätzel M. A low-cost high-efficiency solar cell based on dye-sensitized colloidal $\mathrm{TiO}_{2}$ films. Nature, 1991, 353: 737-740

2 Grätzel M. Photoelectrochemical cells. Nature, 2001, 414: 332-337

3 Grätzel M. Recent advances in sensitized mesoscopic solar cells. Acc Chem Res, 2009, 42: 1788-1798

4 Nazeeruddin M, Kay A, Rodicio I, et al. Conversion of light to electricity by cis- $\mathrm{X}_{2}$ bis $\left(2,2^{\prime}\right.$-bipyridyl-4,4'-dicarboxylate) ruthe-nium(II) charge-transfer sensitizers $\left(\mathrm{X}=\mathrm{Cl}^{-}, \mathrm{Br}^{-}, \mathrm{I}^{-}, \mathrm{CN}^{-}\right.$, and $\left.\mathrm{SCN}^{-}\right)$on nanocrystalline $\mathrm{TiO}_{2}$ electrodes. J Am Chem Soc, 1993, 115: 6382-6390

5 Grätzel M. Dye-sensitized solar cells. J Photochem Photobiol C: Photochem Rev, 2003, 4: 145-153

6 Winder, Matt G, Hummelen C, et al. Sensitization of low band gap polymer bulk heterojunction solar cells. Thin Solid Films, 2002, 404: 373-379

7 Giuseppe C, Gatetabo D. Red sicilian orange and purple eggplant fruits as natural sensitizers for dye-sensitized solar cells. So1 Energy Mater So1 Cells, 2008, 92: 1341-1346

8 Tennakone K, Bandaranayake P, Jayaweera P, et al. Dye-sensitized composite semiconductor nanostructures. Physica E, 2002, 14: 190196

9 Grätzel M. Sol-gel processed $\mathrm{TiO}_{2}$ films for photovoltaic applications. J Sol-Gel Sci Technol, 2001, 22: 7-13

10 Wang L, Luo Y, Huang S. Fabrication and optimization of $\mathrm{TiO}_{2}$ film for dye-sensitized solar cells. Chin Sci Bull, 2011, 56: 1354-1359

11 Lee W J, Ramasamy E, Leed Y, et al. Glass frit overcoated silver grid lines for nano-crystalline dye sensitized solar cells. J Photochem Photobiol A, 2006, 183: 133-137

12 Rani S, Suri P, Shishodia P K, et al. Synthesis of nanocrystalline ZnO powder via sol-gel route for dye-sensitized solar cells. So1 Energy Mater So1 Cells, 2008, 92: 1639-1645

13 Geens W, Poortmans J, Suresh C, et al. Analytical study of PPV-oligomer and $\mathrm{C}_{60}$-based devices for optimizing organic solar cells. So1 Energy Mater So1 Cells, 2000, 6: 43-45

14 Ganesan S, Muthuraaman B, Mathew V, et al. Performance of a new polymer electrolyte incorporated with diphenylamine in nanocrystalline dye-sensitized solar cell. So1 Energy Mater So1 Cells, 2008, 92: 1718-1722

15 Shi C, Ge Q, Li B, et al. Influence of additives on the performance of electrolytes in dye-sensitized solar cells. Chin J Chem Phys, 2008, 24: 2327-2330

$16 \mathrm{Wu} \mathrm{M}$, Lin X, Anders $\mathrm{H}$, et al. A novel catalyst of $\mathrm{WO}_{2}$ nanorod for the counter electrode of dye-sensitized solar cells. Chem Commun, 2011, 47: 4535-4537

17 Wu M, Lin X, Anders H, et al. Low-cost molybdenum carbide and 
tungsten carbide counter electrodes for dye-sensitized solar cells. Angew Chem Int Ed, 2011, 50: 3520-3524

18 Jeon S, Kim C, Ko J, et al. Spherical polypyrrole nanoparticles as a highly efficient counter electrode for dye-sensitized solar cells. J Mater Chem, 2011, 21: 8146-8151

19 Burnside S D, Shnalover V, Barbe C, et al. One-step formation and characterization of $\mathrm{Zn}$ (II)-Cr(III) layered double hydroxides, $\mathrm{Zn}_{2} \mathrm{Cr}(\mathrm{OH})_{6} \mathrm{X}\left(\mathrm{X}=\mathrm{Cl}, 1 / 2 \mathrm{SO}_{4}\right)$. J Chem Mater, 1998, 10: 2419-2425

20 Cameron P J, Peter L M. Characterization of titanium dioxide blocking layers in dye-sensitized nanocrystalline solar cells. J Phys Chem B, 2003, 107: 14394-14440

21 Wu J, Hao S, Lan Z, et al. An all-solid-state dye-sensitized solar cell-based poly ( $\mathrm{N}$-alkyl-4-vinyl-pyridine iodide) electrolyte with efficiency of 5.64\%. J Am Chem Soc, 2008, 130: 11568-11569

22 Wu J, Yue G, Xiao Y, et al. Application of a polymer heterojunction in dye-sensitized solar cells. Electrochim Acta, 2010, 55: 5798-5802

23 Yue G, Wu J, Xiao Y, et al. Flexible dye-sensitized solar cell based on PCBM/P3HT heterojunction. Chin Sci Bull, 2011, 56: 325-330

24 Popov A, Geske D. Voltammetric evaluation of the stability of trichloride, tribromide, and triiodide ions in nitromethane, acetone, and acetonitrile. J Am Chem Soc, 1958, 80: 1340-1352

$25 \mathrm{Wu}$ J, Li Q, Fan L, et al. High-performance polypyrrole nanoparticles counter electrode for dye-sensitized solar cells. J Power Sources,
2008, 181: 172-176

26 Guo H, Li Y, Fan L, et al. Voltammetric behavior study of folic acid at phosphomolybdic-polypyrrole film modified electrode. Electrochim Acta, 2006, 51: 6230-6237

27 Li Q, Wu J, Tang Q, et al. Application of microporous polyaniline counter electrode for dye-sensitized solar cells. Electrochem Commun, 2008, 10: 1299-1302

28 Huang J, Millerb P F, de Mellob J C, et al. Influence of thermal treatment on the conductivity and morphology of PEDOT/ PSS films. Synth Met, 2003, 139: 569-572

29 Aasmundtveit K, Samuelsen E, Pettersson L, et al. Structure of thin films of poly (3,4-ethylenedioxythiophene). Synth Met, 1999, 101: $561-564$

30 Senadeera R, Fukuri N, Saito Y, et al. Volatile solvent-free solidstate polymer-sensitized $\mathrm{TiO}_{2}$ solar cells wit poly (3, 4-ethylenedioxythiophene) as a hole-transporting medium. Chem Commun, 2005, 7: 2259-2261

31 Papageorgiou N, Moser W, Gratzel M. An iodine/triiodide reduction electrocatalyst for aqueous and organic media. J Electrochem Soc, 1997, 144: 876-884

32 Papageorgiou N, Liska P, Kay A, et al. Mediator transport in multilayer nanocrystalline photoelectrochemical cell configurations. J Electrochem Soc, 1999, 146: 898-907

Open Access This article is distributed under the terms of the Creative Commons Attribution License which permits any use, distribution, and reproduction in any medium, provided the original author(s) and source are credited. 